\title{
ERRATUM
}

L. S. Pinto $\cdot$ L. M. Vieira $\cdot$ M. N. Pons

M. M. R. Fonseca $\cdot$ J. C. Menezes

\section{Morphology and viability analysis of Streptomyces clavuligerus in industrial cultivation systems}

Published online: 28 May 2004

(C) Springer-Verlag 2004

\section{Bioprocess Biosyst Eng (2004) 26: 177-184}

Due to an unfortunate error, the addresses of the authors were incomplete and are published correct here.

The online version of the original article can be found at http:// dx.doi.org/10.1007/s00449-003-0349-6

L. S. Pinto · M. M. R. Fonseca · J. C. Menezes

Centre for Biological and Chemical Engineering, IST,

Technical University of Lisbon, Av. Rovisco Pais,

1049-001 Lisbon, Portugal

L. S. Pinto · L. M. Vieira

Laboratório de Microbiologia, CIPAN, S.A.,

Vala-do-Carregado,

2601-906 Castanheira do Ribatejo, Portugal

M. N. Pons $(\square)$

Laboratoire des Sciences du Génie Chimique,

CNRS-ENSIC-INPL, 1, Rue Grandville,

BP 451, 54001 Nancy, France

E-mail: Marie-Noelle.Pons@ensic.inpl-nancy.fr

Tel.: + 33-83175277

Fax: $+33-83175326$ 